\title{
Article \\ Schuurs-Hoeijmakers Syndrome (PACS1 Neurodevelopmental Disorder): Seven Novel Patients and a Review
}

\author{
Jair Tenorio-Castaño ${ }^{1,2,3,4}$, Beatriz Morte ${ }^{1,3,+}$, Julián Nevado ${ }^{1,3,4,6} \oplus$, Víctor Martinez-Glez ${ }^{1,4,6,7} \oplus$, \\ Fernando Santos-Simarro 1,3,4,7, Sixto García-Miñaúr 1,4,7, María Palomares-Bralo 1,3,4,6, Marta Pacio-Míguez 1,3,4,6, \\ Beatriz Gómez ${ }^{1,3}$, Pedro Arias ${ }^{1,2}$, Alba Alcochea ${ }^{8}$, Juan Carrión ${ }^{8}$, Patricia Arias ${ }^{8}$, Berta Almoguera ${ }^{1,3,9}$, \\ Fermina López-Grondona ${ }^{3,9}$, Isabel Lorda-Sanchez ${ }^{1,9}$, Enrique Galán-Gómez ${ }^{10}$, Irene Valenzuela ${ }^{4,11} \mathbb{B}^{1}$, \\ María Pilar Méndez Perez ${ }^{12}$, Ivón Cuscó ${ }^{11}$, Francisco Barros ${ }^{1,13}$, Juan Pié ${ }^{1,14}{ }^{1}$, , Sergio Ramos ${ }^{1,2}$, \\ Feliciano J. Ramos ${ }^{1,14,+} \oplus$, Alma Kuechler ${ }^{15}$, Eduardo Tizzano ${ }^{4,11}$, Carmen Ayuso ${ }^{1,3,9}{ }^{\circledR}$, Frank J. Kaiser ${ }^{15,16}$, \\ Luis A. Pérez-Jurado ${ }^{1,5,+}{ }^{1}$, Ángel Carracedo ${ }^{1,13,17}{ }^{\mathbb{B}}$, The ENoD-CIBERER Consortium ${ }^{\dagger}$, The SIDE Consortium ${ }^{3}$ \\ and Pablo Lapunzina $1,2,3,4,7, *,+$ (i)
}

check for

updates

Citation: Tenorio-Castaño, J.; Morte, B.; Nevado, J.; Martinez-Glez, V.; Santos-Simarro, F.; García-Miñaúr, S.; Palomares-Bralo, M.; Pacio-Míguez,

M.; Gómez, B.; Arias, P.; et al.

Schuurs-Hoeijmakers Syndrome (PACS1 Neurodevelopmental Disorder): Seven Novel Patients and a Review. Genes 2021, 12, 738. https://doi.org/10.3390/ genes12050738

Academic Editor: Allison D. Ebert

Received: 8 April 2021

Accepted: 2 May 2021

Published: 13 May 2021

Publisher's Note: MDPI stays neutral with regard to jurisdictional claims in published maps and institutional affiliations.

Copyright: (c) 2021 by the authors. Licensee MDPI, Basel, Switzerland. This article is an open access article distributed under the terms and conditions of the Creative Commons Attribution (CC BY) license (https:// creativecommons.org/licenses/by/ $4.0 /)$.
1 CIBERER, Centro de Investigación Biomédica en Red de Enfermedades Raras, ISCIII, Melchor Fernández Almagro 3, 28029 Madrid, Spain; jaira.tenorio@salud.madrid.org (J.T.-C.); bmorte@ciberer.es (B.M.); jnevadobl@gmail.com (J.N.); v.martz.glez@gmail.com (V.M.-G.); fernando.santos@salud.madrid.org (F.S.-S.); sixto.garciamin@gmail.com (S.G.-M.); mpalomares.ingemm@gmail.com (M.P.-B.); martapaciomiguez@gmail.com (M.P.-M.); bgomez@ciberer.es (B.G.); palajara@gmail.com (P.A.); balmoguera@hotmail.com (B.A.); ilorda@fjd.es (I.L.-S.); francisco.barros@usc.es (F.B.); juanpie@unizar.es (J.P.); ramossorigue@gmail.com (S.R.); framos@unizar.es (F.J.R.); CAyuso@fjd.es (C.A.);

luis.perez@upf.edu (L.A.P.-J.); angel.carracedo@usc.es (A.C.)

2 Overgrowth Syndromes Laboratory, INGEMM, Instituto de Genética Médica y Molecular, IdiPAZ, Hospital Universitario la Paz, Universidad Autónoma de Madrid (UAM), 28046 Madrid, Spain

3 The SIDE Consortium: Spanish Intellectual Disability Exome Consortium, 28046 Madrid, Spain; fermina.lopez@quironsalud.es

4 Ithaca, European Reference Network, Hospital Universitario La Paz, 28046 Madrid, Spain; mvalenzuela@vhebron.net (I.V.); etizzano@vhebron.net (E.T.)

5 Genetics Unit, Universitat Pompeu Fabra, Barcelona, Spain and Institut Hospital del Mar D'Investigacions Mediques (IMIM), 08002 Barcelona, Spain

6 Structural and Functional Genomics-INGEMM, Instituto de Genética Médica y Molecular, IdiPAZ, Hospital Universitario la Paz, Universidad Autónoma de Madrid (UAM), 28046 Madrid, Spain

7 Clinical Genetics-INGEMM, Instituto de Genética Médica y Molecular, IdiPAZ, Hospital Universitario la Paz, Universidad Autónoma de Madrid (UAM), 28046 Madrid, Spain

8 FEDER (Spanish Federation for Rare Diseases), Calle del Dr. Castelo 49, 28009 Madrid, Spain; direccion@enfermedades-raras.org (A.A.); feder@enfermedades-raras.org (J.C.); infofundacionfeder@enfermedades-raras.org (P.A.)

9 Department of Genetics \& Genomics, Instituto de Investigación Sanitaria-Fundación Jiménez Díaz University Hospital, Universidad Autónoma de Madrid (IIS-FJD, UAM), 28046 Madrid, Spain

10 Clinical Genetics, Head of the Pediatrics Service, Hospital Materno Infantil de Badajoz, Complejo Hospitalario Universitario de Badajoz, Professor of Pediatrics, Director of the Department of Biomedical Sciences, Faculty of Medicine, University of Extremadura, 06110 Plasencia, Spain; enrique.galangomez@gmail.com

11 Department of Clinical and Molecular Genetics, Vall d'Hebron University Hospital and Medicine Genetics Group, Vall d'Hebron Research Institute, 08002 Barcelona, Spain; icusco@vhebron.net

12 Clinical Genetics, Hospital Materno Infantil de Badajoz, Complejo Hospitalario Universitario de Badajoz, University of Extremadura, 06006 Badajoz, Spain; mariapilar.mendez@salud-juntaex.es

13 Fundación Pública Galega de Medicina Xenómica, SERGAS, Instituto de Investigación Sanitaria de Santiago (IDIS), 15702 Santiago de Compostela, Spain

14 Unit of Clinical Genetics, Service of Paediatrics, University Clinic Hospital' Lozano Blesa' and Unit of Clinical Genetics and Functional Genomics, Department of Pharmacology-Physiology, School of Medicine, University of Zaragoza, CIBERER-GCV02 and ISS-Aragón, 50001 Zaragoza, Spain

15 Institute of Human Genetics, University Hospital Essen, University Duisburg-Essen, 45147 Essen, Germany; almu@mti.uni-jena (A.K.); Frank.Kaiser@uk-essen.de (F.J.K.)

16 Center for Rare Disease/Zentrum für Seltene Erkrankungen (EZSE), University Hospital Essen, 45276 Essen, Germany

17 Centro de Investigación en Medicina Molécula y Enfermedades Crónicas (CIMUS), Universidade de Santiago de Compostela, 15702 Santiago de Compostela, Spain

* Correspondence: plapunzina@gmail.com

+ Authors are members of the The ENoD-CIBERER Consortium. 


\begin{abstract}
Schuurs-Hoeijmakers syndrome (SHMS) or PACS1 Neurodevelopmental disorder is a rare disorder characterized by intellectual disability, abnormal craniofacial features and congenital malformations. SHMS is an autosomal dominant hereditary disease caused by pathogenic variants in the PACS1 gene. PACS1 is a trans-Golgi-membrane traffic regulator that directs protein cargo and several viral envelope proteins. It is upregulated during human embryonic brain development and has low expression after birth. So far, only 54 patients with SHMS have been reported. In this work, we report on seven new identified SHMS individuals with the classical c.607C > T: p.Arg206Trp PACS1 pathogenic variant and review clinical and molecular aspects of all the patients reported in the literature, providing a summary of clinical findings grouped as very frequent ( $\geq 75 \%$ of patients), frequent (50-74\%), infrequent (26-49\%) and rare (less than $\leq 25 \%)$.
\end{abstract}

Keywords: Schuurs-Hoeijmakers syndrome; intellectual disability; PACS1; rare disorders; phosphofurin acidic cluster sorting protein 1; pathogenic variant c.607C > T

\title{
1. Introduction
}

Schuurs-Hoeijmakers syndrome or PACS1 Neurodevelopmental disorder (MIM\# 615009) is a rare autosomal dominant disease characterized by distinctive craniofacial features, intellectual disability (ID) with variable degrees of neurodevelopmental delay and congenital anomalies. It was initially reported in 2012 in two unrelated patients with remarkably similar facial features and ID [1]. A few years later a review of 17 additional individuals plus the two original patients were described in a systematic review [2]. As common features included a distinctive facial appearance, delayed speech and delayed psychomotor development/ID ranging from mild to moderate. Most patients had anomalies in the eyes, nose, heart, and gastrointestinal system. After this first review, further patients were reported mainly from series of patients with ID evaluated through massive paralleled sequencing studies [3-14]. Remarkably, almost all patients show the same heterozygous de novo PACS1 variant c.607C > T that results in exchange of an arginine residue to a tryptophan at position 203 and is assumed to be a gain of function variant. Up to date, about 54 patients have been reported, all of them with a striking similar facial phenotype and with pathogenic change in PACS1.

PACS1 codes for the Phosphofurin Acidic Cluster Sorting Protein 1, which is involved in the localization of trans-Golgi network membrane proteins. In vivo functional assays were performed in the initial report of the SHMS, demonstrated that zebrafish embryos expressing the Arg203Trp change showed craniofacial abnormalities. This might be due to the inhibition of Pacs1's ability to mediate the migration and specification of Sox10 in neural crest cells [1].

In this work, we report on seven novel SHMS patients all with the typical Arg203Trp variant. We systematically review all the cases reported so far providing a summary of clinical finding grouped in very frequent ( $\geq 75 \%$ of patients), frequent $(50-74 \%)$, infrequent $(26-49 \%)$ and rare (less than $\leq 25 \%)$.

\section{Materials and Methods}

All new patients reported herein were evaluated by clinical geneticists because of the association of ID and distinctive craniofacial features. Patient 4 was recruited by the Undiagnosed Rare Disease Program (ENoD) of CIBERER. This study was approved by the Medical Ethics Committee of the Hospital Universitario La Paz, IdiPAZ (CEIC-HULPPI3509), and all participants signed a specific informed consent. None of the parents were consanguineous and none of the patients had any remarkable information regarding the perinatal period. A detailed description of the clinical features of all the patients reported here is listed in Supplementary Table S1 and facial phenotypes are showed in Figure 1. 


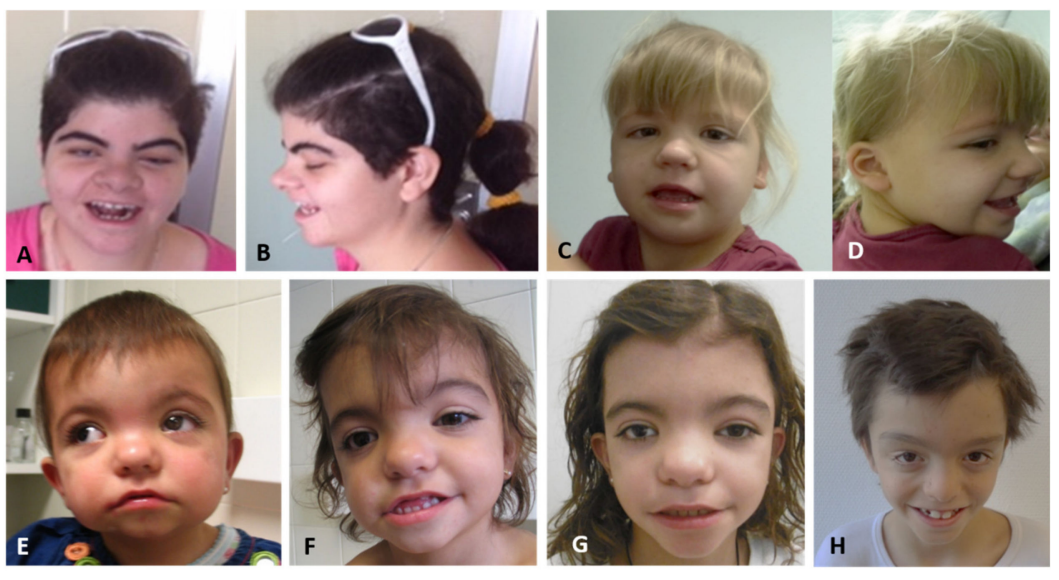

Figure 1. Facial phenotypes of four of the novel patients with PACS1 pathogenic variants. (A,B) patient $1 ;(\mathbf{C}, \mathbf{D})$ patient $7 ;(\mathrm{E}-\mathrm{G})$ patient 4 and $(\mathbf{I})$ patient 6.

On molecular level, patients were diagnosed by either clinical exome sequencing (CES; Sophia Genetics, Boston, MA) or whole exome sequencing (WES) in singleton or trio analyses. Briefly, sequencing was carried out in NextSeq500 or HiSeq4000 platforms (Illumina, San Francisco, California, USA) following the manufacturer's instructions. Inhouse pipelines for bioinformatic analysis were developed to perform quality control (QC) and variant annotation. A suite of QC, scripts that facilitate data quality assessment, was applied. QC also included an assessment of total reads, library complexity, capture efficiency, coverage distribution ( $95 \%$ at $\geq 20 x$, capture uniformity, raw error rates, $\mathrm{Ti} / \mathrm{Tv}$ ratio in coding regions (typically 3.2 for known sites and 2.9 for novel sites), distribution of known and novel variants relative to dbSNP and zygosity. An automated pipeline for the annotation of variants was developed as well. Our application returned many types of variant annotations, including dbSNPrs identification, gene names and accession numbers, predicted functional effect, protein positions and, for amino-acid changes (dbNSFP, CADD), conservation scores and several population frequency databases, and known clinical associations along with a vast array of annotations for non-coding sequences derived from ENCODE. Databases for pathogenic variants such as ClinVar (https:/ / www.ncbi.nlm.nih.gov/clinvar/, accessed on February 2021), Human Gene Mutation Database (HGMD) (http:/ / www.hgmd.cf.ac.uk/ac/index.php, accessed on February 2021), Leiden Open Variant Database (LOVD) (https:/ /www.lovd.nl/, accessed on February 2021), Alamut (https:/ / www.interactive-biosoftware.com/alamut-visual/), and Varsome (https:/ / varsome.com/) were also reviewed. Finally, review, classification, and interpretation of the variant was made according to the American College of Medical Genetics and Genomics (ACMGG) guidelines [15]. CNV analysis was performed applying a custom script named "LACONv" (https://github.com/kibanez/LACONv), which was developed in-house.

\section{Results}

We detected seven patients with the same pathogenic variant in PACS1. All of them carried the most common, recurrent, likely gain of function pathogenic variant [(NM_018026.4):c.607C>T (p.Arg203Trp), chr11 (GRCh37): 65978677)].

The c.607C $>\mathrm{T}$ change has been clearly demonstrated to be pathogenic [2]. Segregation analyses showed that none of the parents tested was carrier of the variant, meaning that all probands had a de novo pathogenic variant.

All patients had ID, abnormal speech and distinctive craniofacial features (Figure 1), including downslanting palpebral fissures, bulbous nose, upturned nose, broad nasal bridge, ocular hypertelorism, thin upper lip, low-set ears, wide, tented mouth, full eyebrows and long eyelashes, among others (Table 1). We listed all clinical features of our patients in Supplementary Table S1 and reviewed the clinical findings observed in our 
patients and in all previously reported patients $(\mathrm{N}=61)$ in Table 1 . This table contains a review of the clinical features described in all the 61 cases described in the literature with SHMS (37 males and 24 females). The most common findings, observed in more than $75 \%$ of patients, are ID, speech delay and distinctive craniofacial features. Eye anomalies are observed in $25-75 \%$ of the patients and are useful for diagnosis.

Table 1. Summary of the clinical features of 61 patients (37 males and 24 females) with SHMS/PACS1 Neurodevelopmental disorder included in this paper. Clinical features are organized according to the HPO nomenclature and grouped in very frequent ( $\geq 75 \%$ of patients), frequent ( $50-74 \%$ ), infrequent (26-49\%) and rare (less than $\leq 25 \%$ ) findings. In total, 58 patients were diagnosed after birth and three prenatally.

\begin{tabular}{|c|c|c|}
\hline Trait (HPO) & $\mathbf{N}$ & $\%$ \\
\hline \multicolumn{3}{|c|}{ Very Frequent $(\geq 75 \%)$} \\
\hline Intellectual disability (HP:0001249) & $56 / 58$ & 97 \\
\hline Dysmorphic facial features (HP:0001999) & $49 / 60$ & 82 \\
\hline Speech delay (HP:0000750) & $42 / 55$ & 76 \\
\hline \multicolumn{3}{|c|}{ Frequent $(50-74 \%)$} \\
\hline Seizures (HP:0001250) & $33 / 58$ & 57 \\
\hline \multicolumn{3}{|c|}{ Infrequent (26-49\%) } \\
\hline Global development delay (HP:0001263) & $26 / 58$ & 45 \\
\hline Cognitive impairment (HP:0100543) & $22 / 58$ & 38 \\
\hline Hypotonia (HP:0001290) & $22 / 58$ & 38 \\
\hline Motor delay (HP:0001270) & $21 / 57$ & 37 \\
\hline Cryptorchidism (HP:0000028) & $12 / 39$ & 30 \\
\hline Amenorrhea (HP:0000141) & $3 / 10$ & 30 \\
\hline Constipation (HP:0002019) & $15 / 57$ & 26 \\
\hline Structural brain anomalies (HP:0012443) & $13 / 49$ & 26 \\
\hline \multicolumn{3}{|c|}{ Rare $(\leq 25 \%)$} \\
\hline $\begin{array}{l}\text { Downslanted palpebral fissures } \\
\text { (HP:0000494) }\end{array}$ & $14 / 61$ & 23 \\
\hline Oral aversion (HP:0012523) & $12 / 54$ & 22 \\
\hline Autistic Spectrum Disorder (HP:0000729) & $12 / 56$ & 21 \\
\hline Bulbous nose (HP:0000414) & $13 / 61$ & 21 \\
\hline Microcephaly (HP:0000252) & $13 / 61$ & 21 \\
\hline Ocular Hypertelorism (HP:0000316) & $12 / 61$ & 20 \\
\hline $\begin{array}{l}\text { Eye anomalies (other than colobomata) } \\
\text { (HP:0000478) }\end{array}$ & $12 / 61$ & 20 \\
\hline $\begin{array}{l}\text { Temper tantrums-aggressions } \\
\text { (HP:0025160) }\end{array}$ & $11 / 55$ & 20 \\
\hline Clinodactyly (HP:0030084) & $12 / 61$ & 20 \\
\hline Abnormal skull shape (HP:0002648) & $11 / 61$ & 18 \\
\hline $\begin{array}{l}\text { Single transverse palmar crease } \\
\text { (HP:0000954) }\end{array}$ & $11 / 61$ & 18 \\
\hline Thin upper lip (HP:0000219) & $11 / 61$ & 18 \\
\hline Gastroesophageal reflux (HP:0002020) & $09 / 55$ & 16 \\
\hline Low-set ears (HP:0000369) & $9 / 61$ & 15 \\
\hline Arched eyebrows (HP:0002553) & $9 / 61$ & 15 \\
\hline
\end{tabular}


Table 1. Cont.

\begin{tabular}{|c|c|c|}
\hline Trait (HPO) & $\mathbf{N}$ & $\%$ \\
\hline Failure to thrive (HP:0001508) & $8 / 57$ & 14 \\
\hline Pes planus (HP:0001763) & $8 / 57$ & 14 \\
\hline Myopia (HP:0000545) & $7 / 49$ & 14 \\
\hline Cerebellar hypoplasia (HP:0001321) & $6 / 43$ & 14 \\
\hline Congenital heart defect (HP:0001627) & $7 / 54$ & 13 \\
\hline Wide mouth (HP:0000154) & $8 / 61$ & 13 \\
\hline Retinal coloboma (HP:0000480) & $6 / 47$ & 13 \\
\hline Full eyebrows (HP:0004523) & $7 / 61$ & 12 \\
\hline Long eyelashes (HP:0000527) & $7 / 61$ & 12 \\
\hline $\begin{array}{l}\text { Umbilical hernia- Inguinal hernia } \\
\text { (HP:0001537) }\end{array}$ & $7 / 61$ & 12 \\
\hline Short stature (HP:0004322) & $7 / 57$ & 12 \\
\hline Hypoplastic labia minora (HP:0000064) & $3 / 25$ & 12 \\
\hline Atrial septal defect (HP:0001631) & $6 / 53$ & 11 \\
\hline Patent ductus arteriosus (HP:0001643) & $6 / 53$ & 11 \\
\hline Ventricular septal defect (HP:0001629) & $6 / 53$ & 11 \\
\hline Low birth weight (HP:0001518) & $6 / 56$ & 11 \\
\hline Diastema (HP:00006999 & $6 / 55$ & 11 \\
\hline $\begin{array}{l}\text { Downturned corners of the mouth } \\
\text { (HP:0002714) }\end{array}$ & $7 / 61$ & 11 \\
\hline Anteverted nares (HP:0000463) & $7 / 61$ & 11 \\
\hline Coloboma of choroid (HP:0000567) & $5 / 49$ & 10 \\
\hline Epicanthus (HP:0000286) & $6 / 61$ & 10 \\
\hline Broad nasal bridge (HP:0012811) & $6 / 61$ & 10 \\
\hline Coloboma of optic nerve (HP:0000588) & $5 / 49$ & 10 \\
\hline Upturned nose (HP:0000463) & $6 / 61$ & 10 \\
\hline Flat philtrum (HP:0000319) & $6 / 61$ & 10 \\
\hline Recurrent infections (HP:0002719) & $6 / 61$ & 10 \\
\hline Iris coloboma (HP:0000612) & $5 / 57$ & 9 \\
\hline Upswept anterior hairline (HP:0002236) & $5 / 61$ & 8 \\
\hline Tented mouth (HP:0010804) & $5 / 61$ & 8 \\
\hline G-tube feeding (HP:0040288) & $5 / 61$ & 8 \\
\hline Pectus excavatum (HP:0000767) & $5 / 61$ & 8 \\
\hline Synophrys (HP:0000664) & $4 / 61$ & 7 \\
\hline Camptodactyly (HP:0012385) & $4 / 61$ & 7 \\
\hline Short neck (HP:0000470) & $4 / 61$ & 7 \\
\hline Clumsiness (HP:0002312) & $4 / 61$ & 7 \\
\hline Absent speech (HP:0001344) & $4 / 56$ & 7 \\
\hline Behavioral abnormality (HP:0000708) & $4 / 56$ & 7 \\
\hline Sleep disturbance (HP:0002360) & $4 / 56$ & 7 \\
\hline Abnormality of the kidney (HP:0000077) & $4 / 59$ & 7 \\
\hline
\end{tabular}


Table 1. Cont.

\begin{tabular}{|c|c|c|}
\hline Trait (HPO) & $\mathbf{N}$ & $\%$ \\
\hline Scoliosis (HP:0002650) & $4 / 54$ & 7 \\
\hline Widely spaced nipples (HP:0006610) & $4 / 61$ & 7 \\
\hline $\begin{array}{l}\text { Abnormality of the cerebral white matter } \\
\text { (HP:0002500) }\end{array}$ & $3 / 43$ & 7 \\
\hline Slender finger (HP:0001238) & $4 / 58$ & 7 \\
\hline Coarctation of aorta (HP:0001680) & $3 / 53$ & 6 \\
\hline Posteriorly rotated ears (HP:0000358) & $4 / 61$ & 6 \\
\hline Flat occiput (HP:0005469) & $4 / 61$ & 6 \\
\hline $\begin{array}{l}\text { Eversion of lateral third of lower eyelids } \\
\text { (HP:0007655) }\end{array}$ & $3 / 61$ & 5 \\
\hline Nystagmus (HP:0000639) & $3 / 61$ & 5 \\
\hline Strabismus (HP:0000486) & $3 / 61$ & 5 \\
\hline Round face (HP:0000311) & $3 / 61$ & 5 \\
\hline Low anterior hairline (HP:0000294) & $3 / 61$ & 5 \\
\hline Micrognathia (HP:0000347) & $3 / 61$ & 5 \\
\hline Large for gestational age (HP:0001520) & $3 / 61$ & 5 \\
\hline Tapered finger (HP:0001182) & $3 / 57$ & 5 \\
\hline Dystonia (HP:0001332) & $3 / 54$ & 5 \\
\hline Involuntary movements (HP:0004305) & $3 / 57$ & 5 \\
\hline Hydrocephalus (HP:0000238) & $2 / 42$ & 5 \\
\hline Ataxia (HP:0001251) & $2 / 43$ & 5 \\
\hline Bicuspid aortic valve (HP:0001647) & $2 / 53$ & 4 \\
\hline Patent foramen ovale (HP:0001655) & $2 / 53$ & 4 \\
\hline Astigmatism (HP:0000483) & $2 / 49$ & 4 \\
\hline Microcornea (HP:0000482) & $2 / 49$ & 4 \\
\hline Falls (HP:0002527) & $2 / 49$ & 4 \\
\hline $\begin{array}{l}\text { Increased nuchal translucency } \\
\text { (HP:0010880) }\end{array}$ & $2 / 48$ & 4 \\
\hline Microphthalmia (HP:0000568) & $2 / 57$ & 3 \\
\hline $\begin{array}{l}\text { Upslanted palpebral fissures } \\
\text { (HP:0000582) }\end{array}$ & $2 / 61$ & 3 \\
\hline Triangular face (HP:0000325) & $2 / 61$ & 3 \\
\hline Widow's peak (HP:0000349) & $2 / 61$ & 3 \\
\hline Cleft lip (HP:0410030) & $2 / 61$ & 3 \\
\hline Concave nasal ridge (HP:0011120) & $2 / 61$ & 3 \\
\hline Long philtrum (HP:0000343) & $2 / 61$ & 3 \\
\hline Short philtrum (HP:0000322) & $2 / 61$ & 3 \\
\hline Macrocephaly (HP:0000256) & $2 / 61$ & 3 \\
\hline Tall stature (HP:0000098) & $2 / 61$ & 3 \\
\hline Recurrent otitis media (HP:0000403) & $2 / 61$ & 3 \\
\hline Brachydactyly (HP:0001156) & $2 / 61$ & 3 \\
\hline Broad hallux (HP:0010055) & $2 / 61$ & 3 \\
\hline
\end{tabular}


Table 1. Cont.

\begin{tabular}{cll}
\hline Trait (HPO) & $\mathbf{N}$ & $\mathbf{\%}$ \\
\hline Finger joint hypermobility (HP:0006094) & $2 / 61$ & 3 \\
\hline Long foot (HP:0001833) & $2 / 61$ & 3 \\
\hline Large hands (HP:0001176) & $2 / 61$ & 3 \\
\hline Overlapping toes (HP:0001845) & $2 / 61$ & 3 \\
\hline Epileptic encephalopathy (HP:0200134) & $2 / 61$ & 3 \\
\hline Placental bleeding (HP:0025328) & $2 / 61$ & 3 \\
\hline Inappropriate laughter (HP:0000748) & $3 / 59$ & 3 \\
\hline Repetitive compulsive behavior $\quad$ HP:0008762) & $2 / 58$ & 3 \\
\hline Self-injurious behavior (HP:0100716) & 3 \\
\hline Pulmonary hypoplasia (HP:0002089) & $2 / 58$ & 3 \\
\hline Short ears (HP:0400004) & $2 / 58$ & 3 \\
\hline Almond-shaped eyes (HP:0007874) & $2 / 61$ & 3 \\
\hline Telecanthus (HP:0000506) & $2 / 61$ & 3 \\
\hline Ptosis palpebralis (HP:0000508) & $2 / 61$ & 3 \\
\hline Pleural effusion (HP:0002202) & $2 / 61$ & 3 \\
\hline
\end{tabular}

Features observed in single patients: persistent left superior vena cava, dysplastic aortic and pulmonary valves, large ears ," hearing impairment, ectropion, lens subluxation, Peters' anomaly, irregular optic discs, oval pupils, delayed visual maturation, lacrimal duct stenosis, rethrognatia, frenulum linguae, absent nasal bone, high arched palate, narrow palate, bifid uvula, misplaced teeth, small teeth, micropenis, septate uterus, congenital diaphragmatic hernia, single umbilical artery, volvulus, short bowel syndrome, ectopic anus, poor feeding, neutropenia, leukopenia, finger and toe syndactyly, hip dysplasia, short toe, fibular subluxation, cerebral atrophy, subependymal nodular high-intensity lesions, cerebellar partial agenesis, colpocephaly, megacysterna magna, hypoplasia of corpus callosum, frontal cortical dysplasia, dysarthria, myoclonus, very high pain threshold, placenta previa, oligohydramnios, rigid behavior, anxiety, apnea, urticaria, clubbing nails, pigmented nevi, lipomyelomeningocele, lordosis, cervical ribs.

\section{Discussion}

SHMS or PACS1 Neurodevelopmental disorder was first reported in 2012 and it is a rare cause of ID. Likely, many patients still remain unreported and, although more than 150 patients are currently known, only 61 patients have been published up to date $[1-7,9-12,14,16]$. The disease causing PACS1 variant always occurred de novo and therefore was excluded in the unaffected analyzed parents.

In this paper we review the clinical and molecular aspects of seven more patients with SHMS as well as all the previously reported individuals, and provide a summary of clinical findings (Table 1). The findings observed in a small number of patients are also listed in Table 1. Patients with SHMS may be clinically diagnosed when ID and speech anomalies are associated with a recognizable facial phenotype consistent in round face, full arched eyebrows, ocular hypertelorism, downslanting palpebral fissures, eye anomalies, bulbous nasal tip, wide mouth with long and flat philtrum and tented and thin upper lip with abnormal vermillion.

The PACS1 protein is a trans-Golgi-membrane traffic regulator that directs protein cargo and several viral envelope proteins. It is upregulated during human embryonic brain development and has low expression after birth. Patients with SHMS produce a protein with dominant-negative or gain-of-function effects that lead to the clinical findings 
characteristic of the syndrome [2]. Currently, there are ongoing efforts to develop an anti-sense therapy that would work by binding to the mutant RNA, and stopping the production of the toxic protein that causes the symptoms of the disease (https:/ / www. pacs1foundation.org/research).

In summary, here we report on seven novel patients with SHMS with pathogenic variant in PACS1 and review clinical and molecular findings of all the previously reported patients, providing a comprehensive review of the syndrome. In order to help physicians to recognize the syndrome, the clinical features of the 61 patients are grouped in very frequent ( $\geq 75 \%$ of patients), frequent ( $50-74 \%)$, infrequent $(26-49 \%)$ and rare (less than $\leq 25 \%$ ).

Supplementary Materials: The following are available online at https:/ /www.mdpi.com/article/ 10.3390/genes12050738/s1, title, Table S1: Clinical characteristics of the seven novel patients with SHMS reported in this paper, Table S2: The ENOD Consortium members, S3: The SIDE (Spanish Intellectual Disability Exome) Consortium members.

Author Contributions: P.L. supervised the work, P.L. and J.T.-C. designed the study, P.L. and J.T.-C. wrote the manuscript, P.A. (Pedro Arias) and M.P.M. prepared the samples for N.G.S. studies, B.M., J.N., M.P.-B., M.P.-M, B.A., I.C., F.B., J.P., S.R. and J.T., performed the molecular analysis, F.S.-S., V.M.-G., S.G.-M., F.L.G., I.L., E.G.-G., I.V., F.J.R., A.K., E.T., C.A., F.J.K., L.P.J., Á.C., M.P.M.P., and P.L. reviewed the clinical features of the patients, B.G., B.M. coordinate the project and sample collection, A.A., J.C., and P.A. (Patricia Arias), participated from patients associations. All authors have read and agreed to the published version of the manuscript.

Funding: This work was possible thanks to the funding provided by the project "Proyecto Piloto para la mejora del diagnóstico genético en personas y familias afectadas o con sospecha de padecer enfermedades raras de base genética" of the Ministry of Health, under the grant BOCM-20181126-24 provided by the Consejería de Sanidad de la Comunidad de Madrid. Funding to J.P. and F.J.R. was partially provided by the group research grant DGA/FEDER B32_17R/B32_20R.

Institutional Review Board Statement: The study was conducted according to the guidelines of the Declaration of Helsinki, and approved by the Institutional Review Board (or Ethics Committee) of University Hospital La Paz (XXX).

Informed Consent Statement: Informed consent was obtained from all subjects involved in the study.

Data Availability Statement: The data presented in this study are available on request from the corresponding author. The data are not publicly available due to patient's inform consent restrictions.

Acknowledgments: We would like to thank all patients and families of patients with PACS1 Neurodevelopmental disorder for allowing us to share their data. This work was possible thanks to the funding provided by the project "Proyecto Piloto para la mejora del diagnóstico genético en personas y familias afectadas o con sospecha de padecer enfermedades raras de base genética" of the Ministry of Health, under the grant BOCM-20181126-24 provided by the Consejería de Sanidad de la Comunidad de Madrid. We also thank the contribution of the researchers included in the SIDE Consortium, and the Scientific Committee and collaborators of the Undiagnosed Rare Disease Program, Centre for Biomedical Research on Rare Diseases (ENoD-CIBERER). This project has been funded by the 2017 funds for the strategies of the Ministry of Health, Social Services and Equality that were approved in the CISNS, in support of the implementation of the strategy against rare diseases. We also thank FEDER (Federación Española de Enfermedades Raras) for its kind support and to make possible the development of this Project.

Conflicts of Interest: The authors declare no conflict of interest.

\section{References}

1. Schuurs-Hoeijmakers, J.H.; Oh, E.C.; Vissers, L.E.; Swinkels, M.E.; Gilissen, C.; Willemsen, M.A.; Holvoet, M.; Steehouwer, M.; Veltman, J.A.; de Vries, B.B.; et al. Recurrent de novo mutations in PACS1 cause defective cranial-neural-crest migration and define a recognizable intellectual-disability syndrome. Am. J. Hum. Genet. 2012, 91, 1122-1127. [CrossRef] [PubMed]

2. Schuurs-Hoeijmakers, J.H.; Landsverk, M.L.; Foulds, N.; Kukolich, M.K.; Gavrilova, R.H.; Greville-Heygate, S.; Hanson-Kahn, A.; Bernstein, J.A.; Glass, J.; Chitayat, D.; et al. Clinical delineation of the PACS1-related syndrome-Report on 19 patients. Am. J. Med. Genet. Part A 2016, 170, 670-675. [CrossRef] 
3. Stern, D.; Cho, M.T.; Chikarmane, R.; Willaert, R.; Retterer, K.; Kendall, F.; Deardorff, M.; Hopkins, S.; Bedoukian, E.; Slavotinek, A.; et al. Association of the missense variant p.Arg203Trp in PACS1 as a cause of intellectual disability and seizures. Clin. Genet. 2017, 92, 221-223. [CrossRef]

4. Martinez-Monseny, A.; Bolasell, M.; Arjona, C.; Martorell, L.; Yubero, D.; Arsmtrong, J.; Maynou, J.; Fernandez, G.; Del Carmen Salgado, M.; Palau, F.; et al. Mutation of PACS1: The milder end of the spectrum. Clin. Dysmorphol. 2018, 27, 148-150. [CrossRef] [PubMed]

5. Miyake, N.; Ozasa, S.; Mabe, H.; Kimura, S.; Shiina, M.; Imagawa, E.; Miyatake, S.; Nakashima, M.; Mizuguchi, T.; Takata, A.; et al. A novel missense mutation affecting the same amino acid as the recurrent PACS1 mutation in Schuurs-Hoeijmakers syndrome. Clin. Genet. 2018, 93, 929-930. [CrossRef] [PubMed]

6. Pefkianaki, M.; Schneider, A.; Capasso, J.E.; Wasserman, B.N.; Bardakjian, T.; Levin, A.V. Ocular manifestations of PACS1 mutation. J. AAPOS 2018, 22, 323-325. [CrossRef] [PubMed]

7. Dutta, A.K. Schuurs-Hoeijmakers syndrome in a patient from India. Am. J. Med. Genet. Part A 2019, 179, 522-524. [CrossRef]

8. Gray, K.J.; Wilkins-Haug, L.E.; Herrig, N.J.; Vora, N.L. Fetal phenotypes emerge as genetic technologies become robust. Prenat. Diagn. 2019, 39, 811-817. [CrossRef] [PubMed]

9. Hoshino, Y.; Enokizono, T.; Imagawa, K.; Tanaka, R.; Suzuki, H.; Fukushima, H.; Arai, J.; Sumazaki, R.; Uehara, T.; Takenouchi, T.; et al. Schuurs-Hoeijmakers syndrome in two patients from Japan. Am. J. Med. Genet. Part A 2019, 179, 341-343. [CrossRef] [PubMed]

10. Kurt Colak, F.; Eyerci, N.; Aytekin, C.; Eksioglu, A.S. Renpenning Syndrome in a Turkish Patient: De novo Variant c.607C $>$ T in PACS1 and Hypogammaglobulinemia Phenotype. Mol. Syndromol. 2020, 11, 157-161. [CrossRef] [PubMed]

11. Seto, M.T.; Bertoli-Avella, A.M.; Cheung, K.W.; Chan, K.Y.; Yeung, K.S.; Fung, J.L.; Beetz, C.; Bauer, P.; Luk, H.M.; Lo, I.F.; et al. Prenatal and postnatal diagnosis of Schuurs-Hoeijmakers syndrome: Case series and review of the literature. Am. J. Med Genet. Part A 2020. [CrossRef] [PubMed]

12. Van der Donk, R.; Jansen, S.; Schuurs-Hoeijmakers, J.H.M.; Koolen, D.A.; Goltstein, L.; Hoischen, A.; Brunner, H.G.; Kemmeren, P.; Nellaker, C.; Vissers, L.; et al. Next-generation phenotyping using computer vision algorithms in rare genomic neurodevelopmental disorders. Genet. Med. Off. J. Am. Coll. Med Genet. 2019, 21, 1719-1725. [CrossRef] [PubMed]

13. Lord, J.; McMullan, D.J.; Eberhardt, R.Y.; Rinck, G.; Hamilton, S.J.; Quinlan-Jones, E.; Prigmore, E.; Keelagher, R.; Best, S.K.; Carey, G.K.; et al. Prenatal exome sequencing analysis in fetal structural anomalies detected by ultrasonography (PAGE): A cohort study. Lancet 2019, 393, 747-757. [CrossRef]

14. Wang, X.Y.; Sun, H.; Wu, H.Y. Schuurs-Hoeijmakers syndrome in a child. Zhonghua Er Ke Za Zhi 2018, 56, 63-64. [CrossRef] [PubMed]

15. Richards, S.; Aziz, N.; Bale, S.; Bick, D.; Das, S.; Gastier-Foster, J.; Grody, W.W.; Hegde, M.; Lyon, E.; Spector, E.; et al. Standards and guidelines for the interpretation of sequence variants: A joint consensus recommendation of the American College of Medical Genetics and Genomics and the Association for Molecular Pathology. Genet. Med. Off. J. Am. Coll. Med Genet. 2015, 17, 405-424. [CrossRef] [PubMed]

16. Lusk, L.; Smith, S.; Martin, C.; Taylor, C.; Chung, W. PACS1 Neurodevelopmental Disorder. In GeneReviews ${ }^{\circledR}$; Adam, M.P., Ardinger, H.H., Pagon, R.A., Wallace, S.E., Bean, L.J.H., Mirzaa, G., Amemiya, A., Eds.; NCBI: Seattle, WA, USA, 1993. 